Original

\title{
Use of quantitative PCR to evaluate methods of bacteria sampling in periodontal patients
}

\author{
Hiroshi Masunaga ${ }^{1,2)}$, Wataru Tsutae ${ }^{3)}$, Hyun $\mathrm{Oh}^{1)}$, Naoki Shinozuka ${ }^{3)}$, \\ Noriyoshi Kishimoto ${ }^{4)}$ and Yorimasa Ogata ${ }^{1,2)}$ \\ ${ }^{1)}$ Department of Periodontology, Nihon University School of Dentistry at Matsudo, Chiba, Japan \\ ${ }^{2}$ Research Institute of Oral Science, Nihon University School of Dentistry at Matsudo, Chiba, Japan \\ ${ }^{3}$ Sapporo Immuno Diagnostic Laboratory, Sapporo, Japan \\ ${ }^{4)}$ Kishimoto Clinical Laboratory, Inc., Tomakomai, Japan
}

(Received 8 June and accepted 26 October 2010)

\begin{abstract}
Periodontal disease is associated with specific periodontal pathogens and may persist as gingivitis or progress to more severe disease. The bacteria involved in disease initiation and progression have not been identified. We used quantitative polymerase chain reaction (PCR) to compare the levels of Porphyromonas gingivalis, Tannerella forsythia, and Treponema denticola, and total bacteria detected by different sampling methods. On the basis of the results of clinical examinations, 57 patients were divided into 3 groups: healthy group (group A), gingivitis group (group B), and periodontitis group (group C). Bacterial samples were collected from saliva, mouthwash, and by paper-point sampling of gingival crevicular fluid (GCF), and the samples were analyzed with quantitative PCR targeting 16S rRNA. The numbers of total bacteria in samples of GCF, saliva, and mouthwash were $10^{5}$ to $10^{6}, 10^{8}$, and $10^{7}$, respectively, per milliliter. The number of $P$. gingivalis in GCF samples was lower than 10 in group $\mathrm{A}$; however, in groups $\mathrm{B}$ and $\mathrm{C}$, the values were $10^{3}$ and $10^{4}$, respectively, indicating that the number of $P$. gingivalis increased with worsening clinical status. Findings were similar in the samples of saliva and mouthwash. The numbers of $T$. forsythia showed a pattern similar to that of $P$. gingivalis in all 3 samples.
\end{abstract}

Correspondence to Dr. Yorimasa Ogata, Department of Periodontology, Nihon University School of Dentistry at Matsudo, 2-870-1 Sakaecho-Nishi, Matsudo, Chiba 271-8587, Japan Tel: +81-47-360-9362

Fax: +81-47-360-9362

E-mail: ogata.yorimasa@nihon-u.ac.jp
These results suggest that saliva and mouthwash samples are clinically useful for bacterial testing of periodontal diseases by quantitative PCR. In addition, mouthwash sampling is more feasible and straightforward than saliva sampling. (J Oral Sci 52, 615-621, 2010))

Keywords: subgingival plaque sampling; bacteriological evaluation; polymerase chain reaction; sampling method.

\section{Introduction}

Bacterial plaque is believed to be the principal etiological factor in the onset and progression of periodontitis. Porphyromonas gingivalis and Tannerella forsythia are strong markers of periodontitis in adults, and these species have been linked to the progression of the disease $(1,2)$. In the microbiological diagnosis of periodontal diseases, subgingival plaque is commonly used in detecting and quantifying bacterial species (3-5). Scalers, dental floss, and paper points have been used to sample subgingival plaque, and the technique used may affect the outcome of microbiological analysis. The use of saliva for diagnostic purposes has been the subject of considerable research (6$8)$.

The events that lead to the initiation of periodontal disease are unclear. Reports have described microbial mechanisms that are responsible for the initiation of periodontal attachment loss $(9,10)$. Another hypothesis suggests that direct implantation or transmission of 
periodontal pathogens may occur in the absence of gingival inflammation $(3,11,12)$. Because there are many types of periodontal infection, either mechanism may occur in conjunction with the presence of various microbial colonization sequences.

In this study, we used DNA probe method to characterize the microbiota of samples of gingival crevicular fluid (GCF), saliva, and mouthwash. Direct DNA probe assay of samples can bypass the technical restrictions of anaerobic culture and requires only the selection of appropriate target species. In larger samples, DNA probe methods can detect species below the detection limit of culture-based assay, when the target species are present in numbers above the threshold of the probe assay. Thus, the methods chosen complement each other because the use of a small DNA probe allows detection of species present in low numbers in larger samples, ie, those species that might not be detected by culture (13-16). Irrespective of the microbiological method used to analyze samples, the selection of appropriate subgingival sampling sites becomes critical when assessing whether differences can be detected in diseased sites as compared with control sites. For example, species associated with disease might spread and colonize clinically healthier sites; thus, the microbiota at the healthier site might resemble that at diseased site. This is a particular concern for healthy gingival sites in an oral cavity with gingivitis or periodontal pockets. Thus, to characterize microbiota and periodontal status, we selected sample sites that would reflect the disease state of both the subject and the individual sites.

\section{Materials and Methods \\ Clinical examination}

One trained and calibrated examiner performed all clinical examinations. Periodontal probing depth (PPD), bleeding on probing (BOP), and gingival recession were recorded at 6 sites per tooth. Clinical attachment level (CAL) was calculated using PPD and gingival recession values. Use of all samples was approved by the Committee on the Use of Human Subjects in Research at Nihon University School of Dentistry at Matsudo (EC06-001).

\section{Subjects}

Fifty-seven adults were enrolled in the study and divided into 3 groups based on their clinical status. The healthy group (group A) comprised adult patients with more than 3 teeth in each quadrant of the dentition, no periodontitis with radiographic evidence of alveolar bone loss (as demonstrated by having fewer than 3 sites with PPD greater than $4 \mathrm{~mm}$ ), and BOP in fewer than $10 \%$ of sites. The gingivitis group (group B) included subjects who fulfilled the criteria for the healthy group, but had BOP in more than $10 \%$ of sites. The periodontitis group (group C) comprised adult patients with untreated periodontitis, radiographic evidence of alveolar bone loss in each quadrant of dentition, and more than 4 sites with PPD greater than $6 \mathrm{~mm}$. On clinical testing, PPD, BOP, and alveolar bone level were investigated.

\section{Sampling method}

Participants were instructed to refrain from eating, drinking, and oral hygiene habits for $3 \mathrm{~h}$ before sampling on the day that samples of saliva, mouthwash, and GCF were collected.

\section{GCF sampling}

GCF samples were collected using a paper point. Each previously selected tooth was isolated with sterile cotton rolls, and the supragingival plaque was removed with sterile cotton pellets. A sterilized paper point (\#30) was carefully inserted to the maximum depth of the periodontal pocket and held in position for $10 \mathrm{~s}$. The paper point was then placed in $1 \mathrm{ml}$ phosphate-buffered saline (PBS) containing $0.1 \%$ silica particles. After centrifugation at $3,000 \mathrm{rpm}, 4^{\circ} \mathrm{C}$, for $5 \mathrm{~min}$, the precipitate was combined with $3 \mathrm{ml}$ sterile $\mathrm{H}_{2} \mathrm{O}$ and $50 \mu \mathrm{l}$ concentrated hydrochloric acid. The mixture $(500 \mu \mathrm{l})$ was then centrifuged at 14,000 $\mathrm{rpm}, 4^{\circ} \mathrm{C}$, for $10 \mathrm{~min}$, and the precipitate was combined with $180 \mu \mathrm{l}$ ATL buffer (Qiagen, Tokyo, Japan) and $20 \mu \mathrm{l}$ of $20 \mathrm{mg} / \mathrm{ml}$ Proteinase $\mathrm{K}$ and incubated at $56^{\circ} \mathrm{C}$ for 30 $\min$.

\section{Saliva sampling}

Saliva samples were collected from patients after they had been chewing gum for $150 \mathrm{~s}$. The sample was combined with $250 \mu \mathrm{l}$ LDB buffer (QuickGene DNA whole blood kit S; Fuji Film Co., Ltd, Tokyo, Japan), incubated at $70^{\circ} \mathrm{C}$ for $10 \mathrm{~min}$ with $250 \mu \mathrm{l}$ of $99.5 \%$ ethanol, and vortexed to prepare the lysate.

\section{Mouthwash sampling}

Mouthwash was collected by rinsing the mouth 10 times with $10 \mathrm{ml}$ Gum Dental Rinse ${ }^{\circledR}$ (Sunstar Inc., Osaka, Japan).

All samples (GCF, saliva, and mouthwash) were labeled with the patient's ID and stored at $-20^{\circ} \mathrm{C}$.

\section{Microbiologic examination DNA extraction}

2-mercaptoethanol was added to each sample at a final concentration of $1 \%$ and incubated at room temperature for $1 \mathrm{~h}$. After vortexing to make it homogeneous, $400 \mu \mathrm{l}$ 
was mixed with $600 \mu \mathrm{lPBS}$ and centrifuged at 14,000 rpm, $4^{\circ} \mathrm{C}$, for $10 \mathrm{~min}$, and the supernatant was discarded. The precipitate was combined with $400 \mu \mathrm{l} \mathrm{PBS}$ and $100 \mathrm{mg}$ of 0.1-mm glass beads, placed in a bead-type cell disruptor (MS-100; Tomy Seiko Co., Ltd, Tokyo, Japan), and disrupted at 3,000 rpm for $120 \mathrm{~s}$. After centrifugation at $14,000 \mathrm{rpm}, 4^{\circ} \mathrm{C}$, for $3 \mathrm{~min}, 200 \mu \mathrm{l}$ of the supernatant was subjected to DNA purification using an automatic nucleic acid extraction system (QuickGene-810, Fuji Film Co., Ltd) and the QuickGene DNA whole blood kit S (Fuji Film Co., Ltd). The devices and reagents were used according to the manufacturers' instructions.

\section{Quantitative PCR}

Quantitative PCR was performed using the LightCycler ST-300 (Roche Diagnostics K.K., Tokyo, Japan). Primers and fluorescence-labeled probes were designed for the 16S rRNA gene using LightCycler Probe Design Software 2.0 (Roche Diagnostics K.K.). The sequences are shown in Table 1. The number of total bacteria was determined using the SYBR GREEN I format, and the primers were designed according to a previously reported method (17). In the PCR reaction to determine the number of total bacteria, $5 \mu \mathrm{l}$ DNA was reacted in a $20-\mu \mathrm{l}$ reaction solution containing SYBR Premix Ex Taq (Takara Bio Inc., Kyoto, Japan) and $0.5 \mu \mathrm{M}$ primers. The amplification program consisted of denaturing at $95^{\circ} \mathrm{C}$ for $30 \mathrm{~s}$, followed by 35 cycles of reactions at $95^{\circ} \mathrm{C}$ for $5 \mathrm{~s}, 65^{\circ} \mathrm{C}$ for $15 \mathrm{~s}, 72^{\circ} \mathrm{C}$ for $20 \mathrm{~s}$, and $82^{\circ} \mathrm{C}$ for $3 \mathrm{~s}$. SYBR GREEN I fluorescence was detected during the final step, at $82^{\circ} \mathrm{C}$. During the $65^{\circ} \mathrm{C}$ annealing step, a touch-down PCR program was introduced from the 10th cycle, which reduced the temperature to $50^{\circ} \mathrm{C}$ at a rate of $1^{\circ} \mathrm{C}$ per cycle. In PCR reactions to determine the numbers of periodontal pathogens, $5 \mu \mathrm{l}$ DNA was reacted in a $20-\mu$ reaction solution containing LightCycler Fast Start Master Hybridization Probe (Roche Diagnostics K.K.), $3.0 \mathrm{mM} \mathrm{MgCl}{ }_{2}, 0.5 \mu \mathrm{M}$ primers, and $0.2 \mu \mathrm{M}$ probes. The amplification program consisted of denaturing at $95^{\circ} \mathrm{C}$ for $10 \mathrm{~min}$ followed by 45 cycles of reactions at $95^{\circ} \mathrm{C}$ for $5 \mathrm{~s}, 65^{\circ} \mathrm{C}$ for $15 \mathrm{~s}$, and $72^{\circ} \mathrm{C}$ for $20 \mathrm{~s}$ (P. gingivalis and T. denticola) or $30 \mathrm{~s} \mathrm{(T.} \mathrm{forsythia).} \mathrm{During} \mathrm{the} 65^{\circ} \mathrm{C}$ annealing step, a touch-down PCR program was introduced from the 10th cycle, which reduced the temperature to $60^{\circ} \mathrm{C}$ at a rate of $1^{\circ} \mathrm{C}$ per cycle; LCRed640 fluorescence was detected during this step. The duration of the $72^{\circ} \mathrm{C}$ elongation step was set to $20 \mathrm{~s}$ for $P$. gingivalis and $T$. denticola and $30 \mathrm{~s}$ for $T$. forsythia.

\section{Calibration curves}

P. gingivalis strain ATCC 33277, T. denticola ATCC strain 35405, and T. forsythia strain ATCC 43037 were purchased from the American Type Culture Collection. Streptococcus mitis was isolated from a saliva sample and was used as a control for the number of total bacteria. DNA was purified from these strains using a QIAamp DNA Mini KIT (Qiagen) and subjected to PCR using corresponding primers and the GeneAmp 9700 PCR System (Applied Biosystems, Inc., Foster City, CA, USA). In the PCR reaction, $5 \mu \mathrm{l}$ DNA was reacted in a $20-\mu \mathrm{l}$ reaction solution containing 1 unit of GoTaq Flexi DNA Polymerase (Promega Japan, Tokyo, Japan), 1× GREEN buffer (attached to Taq), $1.5 \mathrm{mM} \mathrm{MgCl}_{2}, 200 \mu \mathrm{M}$ dNTPs, and $0.5 \mu \mathrm{M}$ primers. The amplification program consisted of denaturing at $95^{\circ} \mathrm{C}$ for 2 min followed by 35 cycles of reactions at $95^{\circ} \mathrm{C}$ for $30 \mathrm{~s}, 55^{\circ} \mathrm{C}$ for $30 \mathrm{~s}$, and $72^{\circ} \mathrm{C}$ for 30 s. Amplification was confirmed by $2 \%$ agarose gel electrophoresis, and the remaining products were used for TA cloning. TA cloning was performed using the pGEM-T Vector Systems (Promega Japan). After plasmid purification, the concentration of plasmid was determined by measuring absorbance, and the number of copies was calculated. The 16S rRNA gene is a multicopy gene. In a search of the Oral Pathogen Sequence Databases (http://www.oralgen.lanl.gov/), there were 4 copies/genome in P. gingivalis, 2 copies/genome in T. forsythia and $T$. denticola, and 3 copies/genome in $S$. mitis. The number of plasmid copies was divided by these values to adjust to 1 genome $=1$ bacterium. S. mitis was used as a control because it accounted for the majority of oral indigenous bacteria. Calibration curves were drawn within a 10 -fold serial dilution range of $1 \times 10^{6}$ to $1 \times 10\left(1 \times 10^{2}\right.$ for total bacteria) bacteria/reaction. The number of total bacteria in samples with fewer than $1 \times 10^{2}$ bacteria/reaction could not be estimated because the Escherichia coli-derived genome was detected due to the use of recombinant Taq.

\section{Statistical analysis}

For all parameters, the mean and standard deviation was calculated using the individual subject as the statistical unit. Differences among the 3 investigated groups with respect to total bacteria, $P$. gingivalis, and T. forsythia in each sample were assessed using one-way analysis of variance (ANOVA). The paired $t$ test was used to compare GCF, saliva, and mouthwash samples. A value of $P<0.05$ or $P<0.01$ was considered significant. All statistical analyses were performed using the SAS statistical software package (SAS Institute Inc., NC., USA).

\section{Results}

The 57 subjects were divided into group A (20 subjects), group B (19 subjects), and group C (18 subjects), based on the results of clinical examination. The numbers of 
bacteria determined by quantitative PCR were presented as $\log$ values ranging from $10^{1}$ to $10^{10}$ per milliliter. The $S$. mitis sequence was used as a reference for total bacteria. Figure 1 shows the total numbers of bacteria in samples of GCF, saliva, and mouthwash. The mean total number of bacteria in GCF was approximately $10^{6}$, and there were significant differences between groups $\mathrm{A}$ and $\mathrm{B}$ and groups A and $\mathrm{C}(P<0.05$ for both $)$. The numbers of total bacteria in saliva and mouthwash samples were $10^{8}$ and $10^{7}$, respectively. There were no significant differences between groups $\mathrm{A}, \mathrm{B}$, and $\mathrm{C}$, which confirms equivalent recovery

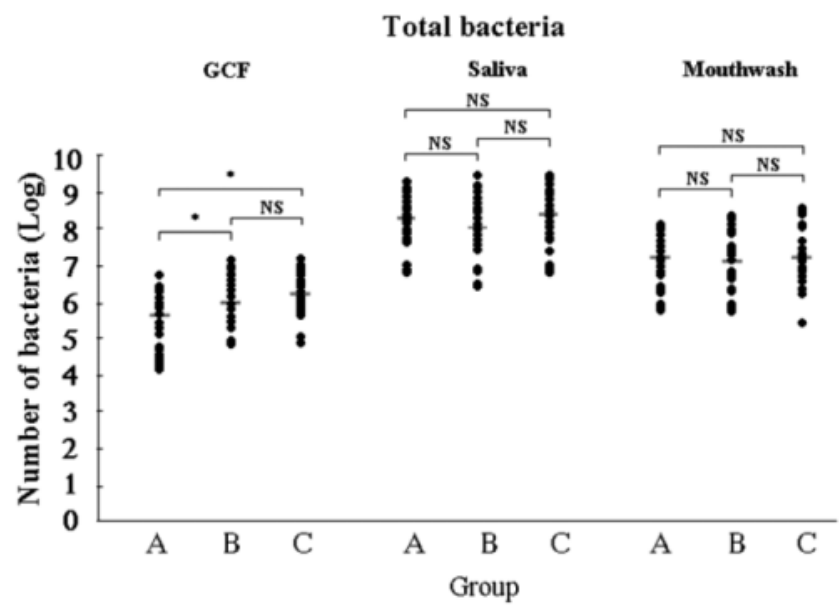

Fig. 1 The number of total bacteria in each sample. Circles represent values in individual subjects; short horizontal bars represent the means of groups. The number of bacteria determined by quantitative PCR is shown as a log value ranging from $10^{1}$ to $10^{10}$. Groups $\mathrm{A}, \mathrm{B}$, and $\mathrm{C}$ refer to the clinical status of subjects. of total bacteria.

Because T. denticola was not detected by PCR in any group, it was not analyzed in the present report. The sequences of $T$. denticola are shown in Table 1.

The number of $P$. gingivalis in the GCF sample was lower than 10 in group $\mathrm{A}$, whereas, in groups $\mathrm{B}$ and $\mathrm{C}$, the numbers were $10^{3}$ and $10^{4}$, respectively (Fig. 2). The number of $P$. gingivalis was significantly higher in groups $\mathrm{B}$ and $\mathrm{C}$, as compared with group $\mathrm{A}(P<0.01)$, and the difference between groups $\mathrm{B}$ and $\mathrm{C}$ was also significant $(P<0.05)$. The number of $P$. gingivalis in saliva was 10 in group $\mathrm{A}$, whereas, in groups $\mathrm{B}$ and $\mathrm{C}$, the numbers were $10^{4}$ and $10^{5}$, respectively, revealing a pattern similar to that of the GCF samples. Findings in GCF and saliva samples

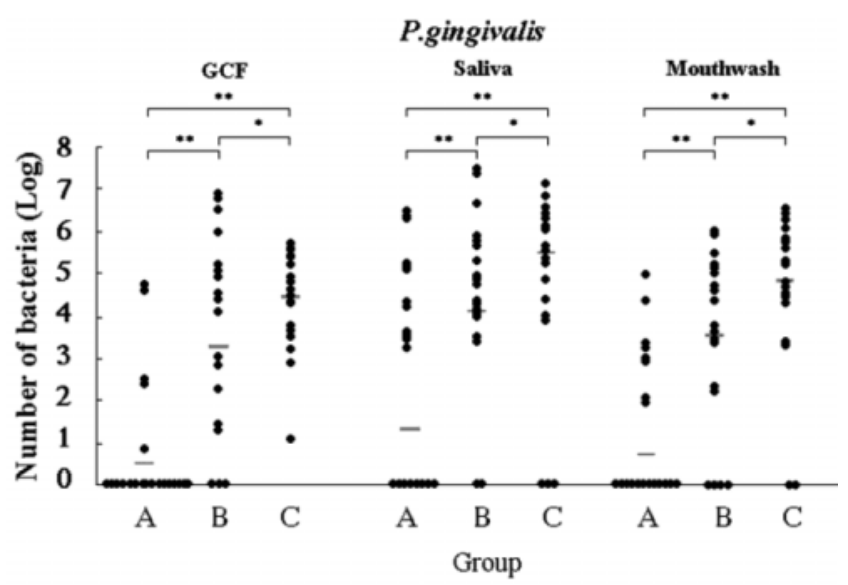

Fig. 2 The number of Porphyromonas gingivalis in each sample, as determined by quantitative PCR, shown as a log value ranging from $10^{1}$ to $10^{8}$.

Table 1 Primers and fluorescence-labeled probe sequence

\begin{tabular}{|c|c|c|}
\hline $\begin{array}{l}\text { Target Gene } \\
\text { (16SrRNA gene) }\end{array}$ & Base position & Sequence $\left(5^{\prime} \rightarrow 3^{\prime}\right)$ \\
\hline $\begin{array}{l}\text { Total bacteria } \\
\text { (\#EU156760) }\end{array}$ & $\begin{array}{l}182-200 \\
648-623\end{array}$ & $\begin{array}{l}\text { TCCTACGGGAGGCAGCAGT } \\
\text { GGACTACCAGGGTATCTAATCCTGTT }\end{array}$ \\
\hline $\begin{array}{l}\text { Porphyromonas gingivalis } \\
\text { (\#AF414809) }\end{array}$ & $\begin{array}{l}702-721 \\
1106-1086 \\
949-978 \\
982-1006\end{array}$ & $\begin{array}{l}\text { AGGCAGCTTGCCATACTGCG } \\
\text { ACTGTTAGCAACTACCGATGT } \\
\text { AACCTTACCCGGGATTGAAATGTAGATGAC-FL(1) } \\
\text { LCRed640(2)-TGGTGAAAACCGTCTTCCCTTCGGG-p(3) }\end{array}$ \\
\hline $\begin{array}{l}\text { Tannerella forsythia } \\
\text { (\#AB035460) }\end{array}$ & $\begin{array}{l}115-134 \\
756-735 \\
369-392 \\
395-418\end{array}$ & $\begin{array}{l}\text { GCGTATGTAACCTGCCCGCA } \\
\text { TGCTTCAGTGTCAGTTATACCT } \\
\text { TCAATGGGCGAGAGCCTGAACCAG-FL } \\
\text { LCRed640-AAGTCGCGTGAAGGATGACTGCCC-p }\end{array}$ \\
\hline $\begin{array}{l}\text { Treponema denticola } \\
\text { (\#AF139203) }\end{array}$ & $\begin{array}{l}138-162 \\
453-427 \\
183-204 \\
207-229\end{array}$ & $\begin{array}{l}\text { TAATACCGAATGTGCTCATTTACAT } \\
\text { TCAAAGAAGCATTCCCTCTTCTTCTTA } \\
\text { GCTACGGCTCCGCTTCAGGATG-FL } \\
\text { LCRed640-CCCGCGTCCCATTAGCTGGTTGG-p }\end{array}$ \\
\hline
\end{tabular}

(1) -FL, 3'-terminal FITC label (2) LCRed640-, 5'-terminal LCRed640 label (3) -p , 3'- phosphorylation 
were also similar with respect to statistical significance. In mouthwash samples, the number of $P$. gingivalis was lower than 10 in group A, whereas, in groups B and C, the numbers were $10^{3}$ and $10^{5}$, respectively, revealing a pattern similar to those of the GCF and saliva samples. The number of $P$. gingivalis was significantly higher in groups $\mathrm{B}$ and $\mathrm{C}$ than in group $\mathrm{A}(P<0.01)$, and there was also a significant difference between groups $\mathrm{B}$ and $\mathrm{C}(P<0.05)$. The statistical findings for the three sampling sites were consistent.

The number of $T$. forsythia in the GCF sample was lower than 10 in group $\mathrm{A}$, whereas, in groups B and $\mathrm{C}$, the numbers were $10^{3}$ and $10^{4}$, respectively, indicating that the number of $T$. forsythia increased with worsening clinical condition (Fig. 3). The number of $T$. forsythia was significantly higher in groups $\mathrm{B}$ and $\mathrm{C}$ than in group $\mathrm{A}(P<0.01)$, and the difference between groups $\mathrm{B}$ and $\mathrm{C}$ was also significant $(\mathrm{P}<0.05)$. In saliva samples, the number of T. forsythia was $10^{3}, 10^{4}$, and $10^{5}$ in groups A, $\mathrm{B}$, and $\mathrm{C}$, respectively. The number of $T$. forsythia in the saliva sample was higher than that in the GCF sample in group A. There was a significant difference between groups B and C. The number of $T$. forsythia was significantly higher in groups $\mathrm{B}$ and $\mathrm{C}$ than in group $\mathrm{A}(P$ $<0.05)$, and there was also a significant difference between groups $\mathrm{B}$ and $\mathrm{C}(P<0.05)$. There were significant differences in detection rate between three groups. In mouthwash samples, the number of T. forsythia was $10^{2}$, $10^{3}$, and $10^{4}$ in groups $\mathrm{A}, \mathrm{B}$, and $\mathrm{C}$, respectively, indicating a pattern similar to that of the saliva samples. The $T$. forsythia detection profile in saliva and mouthwash samples was similar.

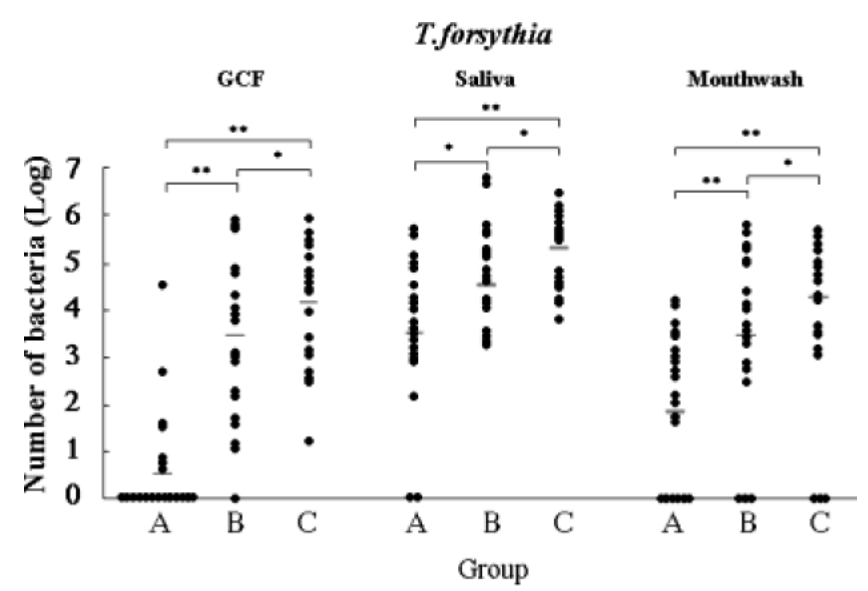

Fig. 3 The number of Tannerella forsythia in each sample, as determined by quantitative PCR, shown as a log value ranging from $10^{1}$ to $10^{7}$.

\section{Discussion}

Periodontal diseases are infectious diseases, and, from an etiological perspective, periodontal pathogens are risk factors. Such pathogens have been detected by various methods used to diagnose periodontal diseases and evaluate the effects of therapy. The culture method was widely adopted in clinical practice after Slots et al. developed various selection media (18); however, only a small number of bacteria species can be cultured, and these are problematic with regard to detection rate. Because of their high sensitivity, PCR techniques may be useful in investigating actual bacterial populations in individual patients. However, PCR requires DNA probes for target DNA $(13,14,19)$. GCF samples have been frequently used in bacterial testing. Quantitative PCR (real-time PCR) is a specific, sensitive, and quantitative method of accurately studying periodontal pathogens, and it is able to detect even a single bacterial cell. The present study used quantitative PCR to compare the detection frequency and number of selected periodontal bacterial species in GCF, saliva, and mouthwash. In particular, we hoped to determine whether a highly sensitive quantitative PCR technique could be used to detect subgingival pathogens in mouthwash. Bacterial testing is now necessary during periodontal treatment. Thus, the need for a straightforward sampling method has increased. Our results indicate that the mouthwash sampling may be such a method.

We compared measurement methods by collecting samples of saliva and mouthwash, as well as GCF. Findings in saliva and mouthwash samples were comparable to those of GCF samples, which suggests that samples can be readily obtained from patients with insufficient saliva secretion or for whom dry field technique is difficult. This expands the range of PCR in bacterial testing. The TaqMan probe used for quantitative PCR requires a short amplification size, which tends to sacrifice primer nonspecificity. Because the $16 \mathrm{~S}$ rRNA gene was targeted, amplified products were elongated in the present study of periodontal pathogens to ensure the specificity of the objective bacteria. The hybridization probe method employed does not require long amplified products, and it is possible to further increase the specificity of the probes, as well as the primers.

We prepared standards by inserting DNA extracted from pure ATCC strains. In this measurement method, calibration curves were prepared with plasmid dilutions. We defined one copy as one molecule and calculated both the number of molecules from the plasmid concentration and the length of the plasmid into which the PCR product was inserted. Bacteria numbers calculated using the calibration curves prepared by this procedure may therefore be more 
accurate.

Subgingival plaque samples have frequently been collected using paper points $(13,19-21)$. Although the sample amount is smaller than that collected by devices such as scalers, reproducibility is high, and the accuracy of testing is reportedly sufficient. The number of total bacteria was similar in the GCF, saliva, and mouthwash samples: $10^{6}, 10^{8}$, and $10^{7}$, respectively. This suggests that mouthwash is as useful as GCF in bacterial testing.

The detection rates of $P$. gingivalis and $T$. forsythia significantly differed at all sampling sites between healthy subjects (group A) and patients with gingivitis (group B) and periodontitis (group C), suggesting that mouthwash can substitute for GCF collection in differentiating healthy adults from patients with periodontitis. The importance of bacterial testing in the diagnosis of periodontal diseases is widely recognized. We investigated the accuracy of data obtained from mouthwash samples, which are easily collected from patients and thus provide a satisfactory substitute for GCF collection.

In most subjects, mouthwash collection was more straightforward. It was also faster. Most importantly, it was shown to be clinically effective in this study. In conclusion, satisfactory findings were obtained using PCR and calibration curves to calculate the numbers of bacteria in samples of GCF, saliva, and mouthwash.

\section{Acknowledgments}

This work was supported in part by Grant-in-Aid for Scientific Research (C; No. 22592319), a grant from the Supporting Project for Strategic Research in Private Universities by the Ministry of Education, Culture, Sports, Science, and Technology, Japan (MEXT), 2008-2012 and a grant of Strategic Research Base Development Program for Private Universities from Ministry of Education, Culture, Sports, Science, and Technology, Japan (MEXT), 2010-2014 (S1001024), and Nihon University Multidisciplinary Research Grant for 2009 and 2010.

\section{References}

1. van Winkelhoff AJ, Loos BG, van der Reijden WA, van der Velden U (2002) Porphyromonas gingivalis, Bacteroides forsythus and other putative periodontal pathogens in subjects with and without periodontal destruction. J Clin Periodontol 29, 1023-1028.

2. Handfield M, Progulske-Fox A, Hillman JD (2005) In vivo induced genes in human diseases. Periodontol $200038,123-134$.

3. Mager DL, Ximenez-Fyvie LA, Haffajee AD, Socransky SS (2003) Distribution of selected bacterial species on intraoral surfaces. J Clin
Periodontol 30, 644-654.

4. Asai Y, Jinno T, Igarashi H, Ohyama Y, Ogawa T (2002) Detection and quantification of oral treponemes in subgingival plaque by real-time PCR. J Clin Microbiol 40, 3334-3340.

5. Gemmell E, Bird PS, Ford PJ, Ashman RB, Golsling P, Hu Y, Seymour GJ (2004) Modulation of the antibody response by Porphyromonas gingivalis and Fusobacterium nucleatum in a mouse model. Oral Microbiol Immunol 19, 247-251.

6. Mager DL, Haffajee AD, Socransky SS (2003) Effects of periodontitis and smoking on the microbiota of oral mucous membranes and saliva in systemically healthy subjects. J Clin Periodontol 30, 1031-1037.

7. Cortelli SC, Feres M, Rodrigues AA, Aquino DR, Shibli JA, Cortelli JR (2005) Detection of Actinobacillus actinomycetemcomitans in unstimulated saliva of patients with chronic periodontitis. J Periodontol 76, 204-209.

8. Rudney JD, Staikov RK (2002) Simultaneous measurement of the viability, aggregation, and live and dead adherence of Streptococcus crista, Streptococcus mutans and Actinobacillus actinomycetemcomitans in human saliva in relation to indices of caries, dental plaque and periodontal disease. Arch Oral Biol 47, 347-359.

9. Rajapakse PS, O’Brien-Simpson NM, Slakeski N, Hoffmann B, Reynolds EC (2002) lmmumization with the RgpA-Kgp proteinase-adhesin complexes of Porphyromonas ginglvalis protects against periodontal bone loss in the rat periodontitis model. Infect lmmun 70, 2480-2486.

10. Yonezawa H, Ishihara K, Okuda K (2001) Arggingipain a DNA vaccine induces protective immunity against infection by Porphyromonas gingivalis in a murine model. Infect Immun 69, 2858-2864.

11. Quirynen M, De Soete M, Dierickx K, van Steenberghe D (2001) The intra-oral translocation of periodontopathogens jeopardises the outcome of periodontal therapy. A review of the literature. $\mathrm{J}$ Clin Periodontol 28, 499-507.

12. Rams TE, Listgarten MA, Slots J (1996) Utility of 5 major putative periodontal pathogens and selected clinical parameters to predict periodontal breakdown in patients on maintenance care. J Clin Periodontol 23, 346-354.

13. Boutaga $\mathrm{K}$, van Winkelhoff AJ, VandenbrouckeGrauls CM, Savelkoul PH (2005) Periodontal pathogens; a quantitative comparison of anaerobic 
culture and real-time PCR. FEMS Immunol Med Microbiol 45, 191-199.

14. Nozaki T, Kusumoto Y, Kitamura M, Hirano H, Kohyama A, Hayakawa M, Takiguchi H, Abiko Y, Murakami S, Okada H (2001) A sensitive method for detecting Porphyromonas ginglvalis by polymerase chain reaction and its possible clinical application. J Periodontol 72, 1228-1235.

15. Nonnenmacher C, Dalpke A, Mutters R, Heeg K (2004) Quantitative detection of periodontopathogens by real-time PCR. J Microbiol Methods 59, 117-125.

16. Lau L, Sanz M, Herrera D, Morillo JM, Martín C, Silva A (2004) Quantitative real-time polymerase chain reaction versus culture: a comparison between two methods for the detection and quantification of Actinobacillus actinomycetemcomitans, Porphyromonas gingivalis, Tannerella forsythensis in subgingival plaque samples. J Clin Periodontol 31, 1061-1069.
17. Sakamoto M, Takeuchi Y, Umeda M, Ishikawa I, Benno Y (2001) Rapid detection and quantification of five periodontopathic bacteria by real-time PCR. Microbiol Immunol 45, 39-44

18. Slots J (2005) Herpesviruses in periodontal diseases. Periodontol 2000 38, 33-62.

19. Lyons SR, Griffen AL, Leys EJ (2000) Quantitative real-time PCR for Porphyromonas gingivalis and total bacteria. J Clin Microbiol 38, 2362-2365.

20. Morillo JM, Lau L, Sanz M, Herrera D, Silva A (2003) Quantitative real-time PCR based on single copy gene sequence for detection of Actinobacillus actinomycetemcomitans and Porphyromonas gingivalis. J Periodontal Res 38, 518-524.

21. Martin FE, Nadkarni MA, Jacques NA, Hunter N (2002) Quantitative microbiological study of human carious dentine by culture and real-time PCR: association of anaerobes with histopathological changes in chronic pulpitis. J Clin Microbiol 40, 1698-1704. 